Whitchurch, C. (2009). "Progressing Professional Careers in UK Higher Education". Perspectives: Policy and Practice in Higher Education 13(1): 3-10.

\title{
Progressing Professional Careers in UK Higher Education
}

\author{
Dr Celia Whitchurch \\ Lecturer in Higher Education \\ Centre for Higher Education Studies \\ University of London Institute of Education
}

\section{Introduction}

This paper arises out of a study conducted for the Leadership Foundation for Higher Education on Professional Managers in UK Higher Education: Preparing for Complex Futures, and focuses on those aspects relating to professional and career development (Whitchurch, 2008a). A paper outlining the first part of the study was published in an earlier issue of perspectives (Whitchurch, 2007). This reviewed understandings in the literature about the roles and identities of professional staff in higher education, and of movements that were occurring in relation to these. The second, empirical part of the study involved interviews with twenty-nine middle and senior managers in three case institutions, and also seven heads of administration from institutions across the UK. This showed how individuals were not only interpreting their given roles in a more active way, but were also moving laterally across functional and organisational boundaries. The final report is available at: http://www.lfhe.ac.uk/publications/research.html.

The study classified the identities of professional staff into four categories:

- Bounded professionals, who locate themselves firmly within organisational and functional boundaries, performing their roles in ways that are relatively prescribed.

- Cross-boundary professionals, who actively use their understanding of boundaries to perform interpretive and translational functions across the institution, and thereby contribute to institutional capacity building.

- Unbounded professionals, who are less cognisant of boundaries, and contribute to broadly based projects across the university such as widening participation and community partnership, performing roles that might be regarded as institutional development.

- Blended professionals, who are appointed on the basis of experience that enables them to carry out mixed portfolios, and to contribute to activity that straddles both professional and academic domains. Such experience may have been acquired in a contiguous environment such as further education, regional development, or the charitable sector. 
A fuller account of this typology, and of the characteristics of each, is given in Whitchurch (2008a and b). This paper offers discussion and analysis of its implications for career and professional development.

\section{Careers and Career Routes}

Notwithstanding efforts by the Association of University Administrators to promote university administration and as a career (AUA, 2003), reasons given by respondents for entering higher education administration tended towards the serendipitous, and included:

- Part-time or vacation work at their institution while a student.

- Contact with someone who worked in a university.

- A wish to be in a particular locality where the university was a major employer.

- A desire to stay in academic environment after undertaking a programme of study.

- A belief in the transferability of an individual's skills and experience from another sector, and that working in higher education would extend this experience.

- (More senior roles) head-hunted by a vice-chancellor or senior manager.

However, once recruited, those who worked in the pre-1992 sector tended to be aware of, and to have followed, a traditional career route, comprising generic roles of increasing seniority, as outlined in Figure 1:

Figure 1: Traditional Career Routes in Pre-1992 Sector

\begin{tabular}{|l|l|}
\hline Generalist Roles & $\begin{array}{l}\text { Specialist Roles eg Finance, Human } \\
\text { Resources }\end{array}$ \\
\hline Head of Administration & Functional Director \\
Academic Registrar & Deputy Director \\
Assistant Registrar & Functional Officer (Head of Section) \\
Administrative Assistant & Assistant Functional Officer \\
Preliminary External Experience & Preliminary External Experience \\
\hline
\end{tabular}

Such career paths reflected the situation in a more homogeneous pre-1992 sector, in which individual roles were expected to be of a comparable nature in different institutions. Thus, an individual in one institution would be assumed to have a similar set of skills and knowledge to those of someone occupying a similar post in another institution, and this was reflected in generic job titles. Career paths were, therefore, 
relatively predictable, and generalist staff were likely to undertake a range of tasks, from academic appointments to research grant administration, from student admissions to examination boards, and from committee servicing to publications. Until the 1980s, generalist staff still occupied specialist roles in personnel, finance and estates (Metcalfe, 1998), which in contemporary institutions would require people who were in possession of the appropriate professional qualifications. In the case studies, twenty-two of the twenty-nine respondents had had what might be seen as 'traditional' career routes, with significant experience in one or more institutions. However, while some professional staff continue to see themselves as making a longterm commitment to higher education, for others, possibly increasing numbers of staff, higher education may comprise a segment of a career that also incorporates other sectors. However, the study suggests that, for both groups, career paths are both more diverse and less clearly defined than in the past.

Of the four categories of professional, cross-boundary professionals appeared to be more explicit than the other groups about consciously planning a career in higher education. They might be seen, therefore, as supplying a cadre of career professionals who move between institutions, whereas bounded professionals were more inclined to find a role that they enjoyed, and either stay in it or seek progression in the same institution. Although unbounded professionals were aware of career possibilities that might be open to them in higher education, and were likely to seize opportunities that came along, they were, at the same time, open to possibilities that might arise outside the higher education sector, and appeared to have less allegiance to it per se than cross-boundary professionals. For blended professionals, developing and embedding their areas of activity into an established field appeared to be a priority, and while all had ambitions to achieve a senior management post, they appeared to keep their options open as to whether this might be in higher education or in a contiguous sector.

Although traditional career paths continue to provide a framework within which to think about individual futures, the advent of increased project working and portfolio careers (Whitchurch, 2006; 2008) has led to a situation that is, in practice, less clearcut. It also reflects wider movements in the workplace, for instance the premium placed by Generation X (in their 30s) and Generation Y (in their 20s) on flexibility to achieve life-work balance, networking and partnership (McCrindle, 2005). Thus, while some long-serving staff may have remained in the sector by default, younger staff do not necessarily anticipate a career for life, with clearly defined transition points, and wish to acquire experience and qualifications that will be distinctive, equipping them for a future that is more uncertain than it was for their predecessors. This is reflected in the use of titles, illustrated by a comment by one manager that staff want titles that will reinforce their association with a task area, rather than with a generic cadre:

"Very few people want to be known as administrative assistant, so if you give them the title of ... student recruitment assistant, or publications assistant, they often feel a lot happier and a lot more confident about talking about their professional competence." 
Thus, professional legitimacy would appear to derive increasingly from a link with functional or project areas, about which individuals feel that they can speak with authority.

This more fluid situation is shown in Figure 2, which illustrates how, alongside formal career paths, people are increasingly extending their experience via, for instance;

- $\quad$ short- and long-term project work;

- institutional outreach and partnership;

- secondments and exchanges;

- qualifications and professional development.

Such opportunities may involve lateral crossovers, and/or activity that is parallel and supplementary to a formal role, and can be used to reinforce an individual's profile in preparation for the next formal, career move.

Figure 2: Contemporary Career Routes

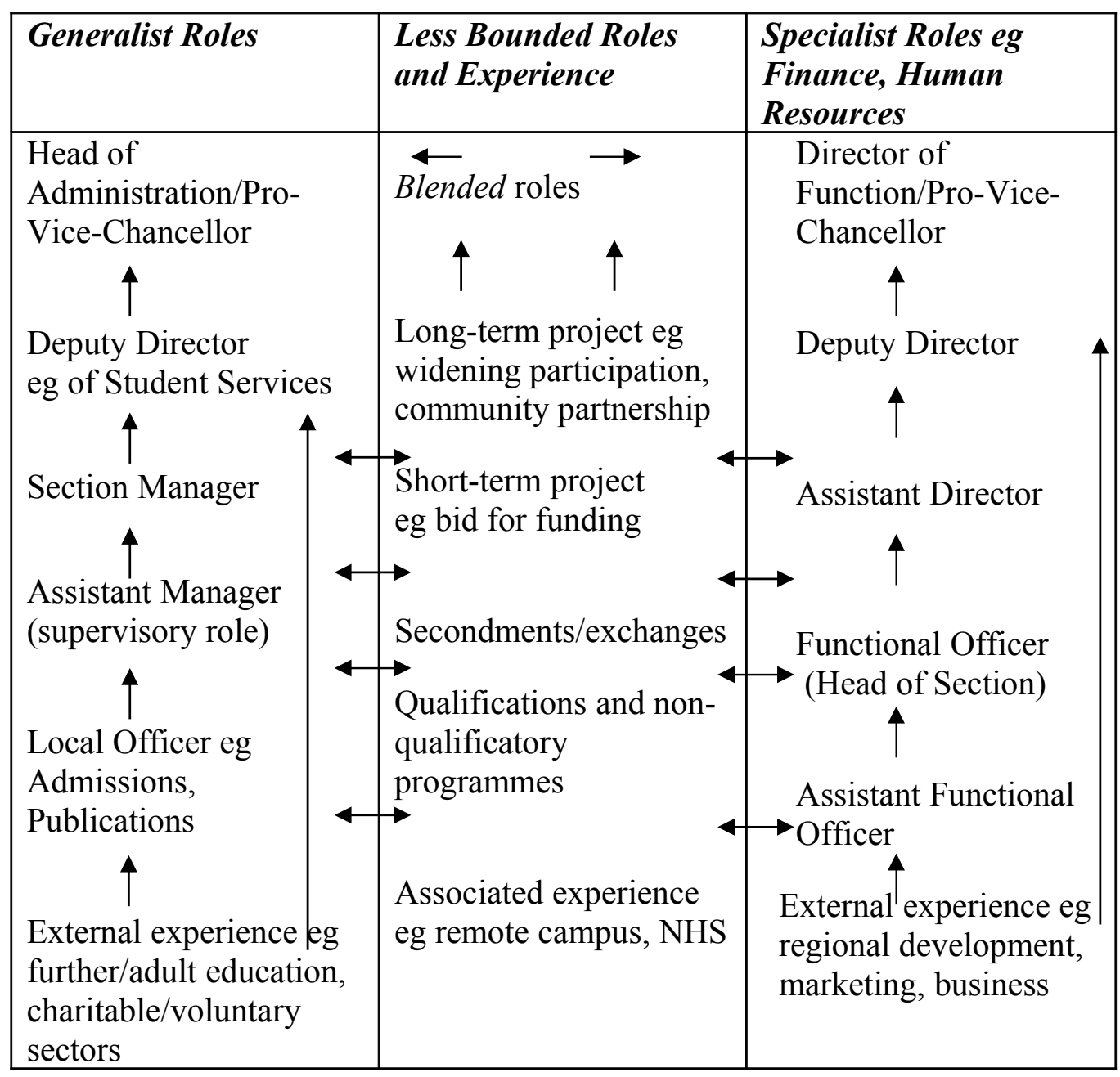


Those in blended roles were less likely to have had a traditional career path through higher education, and to have been appointed on the basis of significant external experience, for instance in the charitable sector, regional development, or further education. They, particularly, seemed to experience dilemmas about possible career directions. Several people spoke of whether they might develop the strategic/policy or service side of their activities, and the difficulty of doing both concurrently. Others saw breadth of experience as being a significant component of career progression:

- "I've always tried to take the next step in another area, so that it moves you forward."

- $\quad$ "I want to develop a regional or national profile ... to be recognised as having some success in developing the university's profile ... [and] to be involved in some of the networks at a more decision making level, rather than at the operational level..."

- "I'm very ambitious... I'm a jack of all trades, I've got knowledge of legislation, budget management, fundraising, staff management, strategic planning ... I want to grow these skills some more... It may well be that I might end up at another university or in the voluntary sector trying to move towards higher management."

Professional staff with mixed backgrounds and experience are likely to see themselves moving into senior, possibly pro-vice-chancellor, posts with a portfolio such as student affairs. It may be, therefore, that working across and beyond boundaries is an increasingly significant factor in enhancing such individuals' career prospects. On the other hand, there may also be risks attached to moving out of the mainstream in order to develop a broader portfolio, for instance, reducing opportunities for line management and budgetary experience that might be required for a more senior post.

A significant number of respondents reported experiencing a lack of career horizons or knowledge of possibilities that were available:

- “... there's not a[n] ... obvious career path ... there's side channels. It's a strange career really. I've always thought 'What do you do?"'

- "Academic administration is not taken seriously enough as a career ..."

Others felt thrown back on their own resources in planning and developing their careers:

- "Rather than growing into something naturally you've got to think about what you've got to offer in a much more strategic way."

- "[Other colleagues] didn't really grasp the nettle and move on, and ... you've got to put your head above the parapet don't you, and go for it."

There was, therefore, evidence that career guidance at local level would be helpful, particularly in the early stages of a career, to assist individuals in seeking, and creating, career opportunities and choices.

It was significant that a number of less bounded forms of professional spoke not only of writing their own job description, but also of the use of annual review to set the next year's agenda, so that it effectively became a rolling job description. This suggests that fixed and detailed job descriptions may not only be unrealistic, but may be unduly constraining, and that roles increasingly reflect the receptiveness of the 
individual to changing institutional contexts and environments. This corresponds with a view of professionalism as being acquired by the construction of an activity portfolio, rather than by membership of a grouping of professionals with a similar profile.

Furthermore, there was evidence that less bounded forms of professional looked outside conventional roles and career routes:

"I saw quite an interesting job recently and thought 'that looks interesting', simply because it doesn't fit any model."

However, less generic roles and career paths are likely to make it more difficult for individuals to plan in advance, and achieve steady progression in their careers, for instance staying five years in a post then moving on. It may be that people will make more rapid lateral moves to gain experience that they could not achieve by waiting for a sequential progression. The issue of mobility was mentioned by a number of respondents, particularly by those who saw themselves as higher education career professionals, as being an advantageous in building a career:

"It is difficult to progress in one institution - those who are able to move have an advantage."

On the one hand, greater mobility can generate a view of professional staff as a:

"national (and international) cadre of mobile and unattached ... managers

without loyalty but with their own (not an institutional) portfolio - the new portfolio successional career managers..." (Duke, 2002: 146).

On the other hand, the study suggests that it may be helpful for institutions to modify a belief that such mobility represents 'disloyalty', in that such individuals may make a more significant contribution to an institution in the period that they are there than longer serving staff. There may need to be, therefore, a revision of the value accorded to professional staff who bring expertise from elsewhere, but move on to gain further experience when they have completed a specific project. There were suggestions by more than one respondent that there was merit in coming into an institution to set up a project with no preconceptions, whereby their opinion would be listened to, whereas after a period of time they would no longer be seen as an "impartial observer".

Thus, it appeared from the study that contemporary staff were less likely than their predecessors to regard themselves as members of a homogeneous professional cadre. The value of a peer group was likely to be seen more in terms of opportunities for networking, raising one's profile, and providing development opportunities. In contemporary institutions, therefore, the term 'professional' may increasingly imply experience that is validated by a portfolio of successfully completed projects, as well as qualification(s), that give external credibility. It may also imply the possession of a network of "weak ties" (Granovetter, 1974), which "are critical to ... creative environment[s] because they allow for rapid entry of new people and rapid absorption of new ideas" (Florida, 2002: 276-277).

\section{Professional and Career Development}

Career paths that are lateral as well as linear have implications for professional development needs and provision. The study sought to update and extend the 
evidence gathered in the literature review (Whitchurch, 2007) through a questionnaire to graduates of three dedicated UK management programmes, two of which led to a formal qualification, as well as through respondent interviews. It was clear from both that, although professional and career development were seen as being linked, provision was of most value when it was tailored to the individual:

- "Unclear career progression pathways make it difficult to select professional development opportunities."

- "The career pathways are not clear, and career advice plus flexible forms of personal development may be a more appropriate alternative to fixed programmes of study leading to a qualification."

Desire to make progress in a career could, therefore, be a significant motivator in overcoming time constraints, which were seen as the major barrier to development activity.

\section{Questionnaire survey}

An overall response rate of $38 \%$ (49/130 individuals) was achieved in relation to the questionnaires. $57 \%$ of the forty-nine respondents classified themselves as 'generalists' and 43\% as 'specialists'. 32\% had professional qualifications, 33\% a master's degree, and 10\% a doctorate before starting their programme.

On all three programmes, participants overwhelmingly cited 'own initiative' (rather than encouragement by a line manager or the institution) as the trigger for their attendance and, for two of the programmes, knowledge of the opportunity came from peer group networks rather than the institution. The third programme appeared to be better publicised and integrated as part of institutional planning for the development of professional staff. $24 \%$ of participants had either paid their own, or made a contribution to, course fees. In the small number of cases where some difficulty was reported in obtaining time to attend programme modules or study time, this had been overcome by negotiation, using annual leave, and/or agreeing that the time would be compensated for out of working hours.

The overwhelming reason for undertaking a programme was to contextualise and broaden knowledge of the higher education policy environment and other types of institution (59\%). In particular, it was seen as important to be able to link specialist and technical knowledge to a more holistic view of institutional activity. This was closely followed by a desire to gain a qualification for the purpose of career progression (56\%), and personal professional development was cited by $41 \%$ of respondents. Although networking and meeting peers was not seen as a compelling reason for deciding to attend a programme, this emerged as a highly valued outcome, and in the case of the non-qualificatory programme, it was ranked as the top outcome. In relation to group mix, it was suggested that it was important not to have too great a disparity between numbers of generalist and specialist staff, and also between levels of experience, so that members of the group could learn from one another. Only one of the programmes included academic staff, and although this enabled individuals to "explore differences of perception in a constructive way", the possibility of tensions also existed, whereby, for instance: 
- Academic colleagues were perceived by professional staff to dominate group work.

- Discussions could be perceived as not relevant by one group or the other.

- Academic staff perceived discussions as lacking rigour.

Nevertheless, a majority of respondents overall said that they would prefer a programme that also included academic colleagues, although the balance of seniority and experience between participants appears to be critical to the success of mixed programmes. There also appeared to be an impression among some respondents that more development opportunities existed for academic than for professional managers.

$68 \%$ of respondents had worked in two or more higher education institutions, and in that sense might be regarded as higher education career professionals. Nevertheless, when asked about the future, $45 \%$ saw moving out of the sector as a possibility, and $49 \%$ mentioned that they saw themselves as moving into a project management role. In response to a question about favoured development opportunities, the response was evenly divided between further qualifications (54\%), secondments and exchanges $(56 \%)$, and mentoring programmes $(53 \%)$ (although a majority of respondents indicated more than one possibility). $24 \%$ said that they would consider a doctorate. While management and/or higher-level qualifications appeared to be seen as an increasingly significant element in career development, bespoke opportunities that were timely and appropriate, such as secondments and mentoring, tended to be favoured over formal programmes that did not lead to a qualification. This may have been because time constraints, as opposed to, for instance, funding availability, were seen as the overwhelming obstacle to participation in development activity.

The questionnaire survey on professional development supported the conclusion of the main study that a significant minority of individuals felt isolated, both in their current roles and institutions, and with respect to peer professionals elsewhere. This was particularly the case in, for instance, departmental 'silos', whereby "Administrative ... staff in academic departments tend to be passed over". This suggests that it would be helpful if institutional thinking about professional development could be linked to internal opportunities such as job rotation schemes.

\section{Interviews}

The evidence gathered from interviews corroborated findings from the questionnaire survey. Four main sources of motivation emerged for attending a development programme, whether in-house or external, qualificatory or non-qualificatory:

- To progress in career/gain promotion.

- To fill gaps in knowledge/skills (ranging from how to read a budget to managing people).

- To deal with specific problems and obtain feedback on performance.

- To gain 'kudos' from a particular qualification or programme. 
It would appear, therefore, that professional staff increasingly favour individualised provision that incorporates feedback on professional practice. As might be expected, however, there were some differences between what those in middle management roles and those in senior roles felt that they required.

\section{Middle managers}

There was a clear preference among middle managers for what one described as "structured learning" within the work environment. Topics that were mentioned included public speaking, presentation skills, report writing, project management and fund-raising. PRINCE qualifications (Projects in Controlled Environments) were referred to by a number of respondents. Others reported undertaking modules that they saw as particularly relevant to them, for instance from a master's programme, rather than attending the entire course (a practice that may be more widespread than progression statistics might suggest). There was a sense that development was most effectively undertaken as a series of loops back and forth between the workplace and the learning environment. In order to obtain the maximum benefit from formal programmes, therefore, there was "a degree of needing to be in a role for while". Furthermore, it was suggested that learning needed to take place in "safe space", in which confidence could be built for new roles, and that in-house courses, alongside colleagues with whom one would be working outside the programme, could be inhibiting in this respect.

Other respondents described how they used project work that they were undertaking within a formal programme to bring together the development of their own professional practice with workplace requirements, and the enhancement of their own effectiveness in their role:

"My own MSc thesis ... is looking at academics' conceptual understanding of the terms 'management' and 'leadership', and where that would come from, how they've constructed it, and if management development in the university has some kind of influence on the understanding that they have."

This respondent had learnt research methods to undertake this work, and was making full use of an academic opportunity to contribute to understandings about the management and leadership development requirements of academic managers.

\section{Senior managers}

A number of respondents commented on the difficulty of finding development opportunities that matched the requirements of day-to-day experience, particularly in relation to ambiguous conditions. The balance and integration of theory and practice in formal programmes, therefore, was felt to be critical, if these were to be of value:

- "I've never found [a development programme] yet that has been useful. Because you go and people say that the objective is to get from A to B, and move through the messy bit in the middle, but no-one has yet to say to me 'these are the really useful things [for] moving through the messy bit'."

- "I just think that everyone can be enriched and enhanced ... it's not necessarily teaching 'this is it'; but there's a way that you can be taught 
certain things ... that different styles are appropriate for different circumstances..."

What emerged as a key issue for senior managers was not only the integration of professional development with day-to-day working, but also the value of one-to-one feedback on practice and performance:

"I can read the theory on my own, but what would be valuable for me would be for someone to say "your performance here was ..."

Another manager saw professional development as most effective when "short sharp bursts", involving feedback, were alternated with a return to the workplace:

"... it needs to be businesslike stuff, intensive feedback and criticism download this, then feed off it for two months and go back to re-charge."

There was a sense, therefore, in which senior managers sought development opportunities that would enable them to grow into making increasingly critical judgements, for instance in relation to risk. They also appeared to incline towards provision that would enable them to both enhance their own practice and expand their comfort zones (one person likened this to development of academic practice through peer review of teaching).

Figure 3 illustrates the perceived advantages and disadvantages of in-house and external provision, and also of programmes that lead to a qualification. There did not appear from the sample to be a difference between middle and senior managers in this respect, although middle managers might find it more difficult to obtain funding for external courses.

Figure 3: Perceived Advantages and Disadvantages of In-house, External and Qualificatory Development Provision

\begin{tabular}{|c|c|c|}
\hline Type of provision & Pros & Cons \\
\hline In house & $\begin{array}{ll}- & \text { Less time } \\
& \text { commitment } \\
- & \text { More targeted }\end{array}$ & $\begin{array}{ll}- & \text { Less 'safe' } \\
& \text { environment } \\
\text { - } & \text { More restricted } \\
& \text { network } \\
\end{array}$ \\
\hline External & $\begin{array}{ll}\text { - } & \text { Networking } \\
& \text { possibilities } \\
\text { - } & \text { Wider perspectives } \\
\end{array}$ & $\begin{array}{l}\text { - } \text { Expensive } \\
\text { - } \text { Time-consuming }\end{array}$ \\
\hline Qualificatory & $\begin{array}{ll}\text { - } & \text { Recognised } \\
\text { credentials } \\
\text { - } & \text { Portable }\end{array}$ & $\begin{array}{ll}\text { - } & \text { Expensive } \\
\text { - } & \text { Time consuming } \\
\text { - } & \text { Big investment if } \\
& \text { not appropriate } \\
\end{array}$ \\
\hline
\end{tabular}

While there was acknowledgement that "it is difficult to provide opportunities for such a diverse group of professionals", even those who felt that there was a satisfactory amount of provision saw it as somewhat "hit and miss". At the same time, some managers also saw it as their responsibility to provide development 
opportunities for their own staff, and ran development programmes for their own teams, with the aim of, for instance:

- Contextualising local agendas in institutional and national agendas.

- Establishing a "sense of community" amongst their staff.

- Providing their staff with networking opportunities.

- Raising confidence levels.

- Promoting the activities of their team at institutional level.

It was clear that just-in-time provision, with a connection to the individual's workplace experience, was favoured by both middle and senior managers. Issues therefore arise about how less formal opportunities might be integrated with formal programmes, how professional staff development relates to the opportunities available for academic staff, and about ways in which the two might be integrated. A number of managers suggested that higher education could learn from the private sector where greater attention was given to nurturing middle managers, since they were the leaders of the future, and that institutions could use their own resources more effectively, for instance calling on business school colleagues to provide tailormade, in-house programmes, and even mentoring.

External programmes, particularly those that were high profile such as the Leadership Foundation Top Management Programme, could also be important 'totems' in signalling senior management potential. There is a sense in which such programmes might be sought, therefore, notwithstanding their precise content, for career purposes. Should such programmes effectively become a requirement for professional staff to progress, demand for them is likely to increase.

\section{Concluding remarks: Implications of the study for career and professional development}

Not only are career paths are becoming less linear but, alongside their formal roles, professional staff are constructing individual portfolios, contributing to a variety of institutional projects, and extending their own professional practice, so that career building has multiple strands. Senior management teams may wish to consider issues arising from these developments, such as:

- Opportunities for professional staff to contribute to institutional projects, acquire additional qualifications, and become involved in cross-institutional networks.

- Opportunities for professional staff to become involved in blended roles, which incorporate elements of academic activity.

- Facilitating transfer from other sectors, for instance by encouraging secondments to and exchanges with contiguous professional environments.

- More flexible working patterns and conditions for staff who wish to build an extended project portfolio. 
The introduction of a common National Framework Agreement for staff in UK higher education in 2006, permitting institutions to design and customise their employment structures around a single pay spine, could give greater latitude for rewarding individuals who extend their roles outwith the precise parameters of a job description (Strike, 2005). However, the emphasis of the Framework on a job evaluation process may, at the same time, restrict the ability of individuals to interpret and develop their roles. Institutions will be obliged to address such issues if they wish to encourage more extended ways of working.

Professional staff have not only become a more diverse grouping, but career pathways and patterns are less well defined than hitherto. Individuals are interpreting their given roles more actively, and also moving laterally across boundaries. Rather than drawing their authority solely from established roles and structures, less bounded forms of professional are emerging who build their credibility increasingly on a personal basis, and construct bespoke career portfolios. Although there may be a greater range of career possibilities, there is also likely to be greater uncertainty, if not risk, attached to individual trajectories. While professional staff themselves have a part to play in raising awareness of their career aspirations, by promoting their contribution to institutional agendas, senior institutional managers, also, have a responsibility to acknowledge movements that are occurring. However, the study suggests that, provided that they are integrated with an individual's professional life, development initiatives can be helpful in raising awareness of opportunities, and increasing the likelihood of individual potentials being realised.

\section{REFERENCES}

Association of University Administrators (2003). A career in higher education administration fact sheet.

http://www.aua.ac.uk/publications.careersinhe.factsheet.aspx. Accessed 17 June 2008.

Duke, C. (2002). Managing the Learning University. Buckingham, Open University Press/SRHE.

Florida, R. (2002). The Rise of the Creative Class. New York, Basic Books.

Granovetter, M. (1974). Getting a Job: A Study of Contacts and Careers. Cambridge, Harvard University Press.

McCrindle, M. (2005). Understanding Generation Y. Conference of the Association of Tertiary Education Management, Perth, Australia.

Metcalfe, R. (1998). How to survive in estates. Take a Minute: Reflections on Modern Higher Education Administration. Ed. H. Thorley. Lancaster, University of Lancaster.

Strike, A. (2005). Evolution of Academic Career Structures in English Universities. OECD Conference on Trends in the Management of Human Resources, Paris. 
Whitchurch, C. (2006). "Who do they think they are? The changing identities of professional administrators and managers in UK higher education." Journal of Higher Education Policy and Management 28(2): 159-171.

Whitchurch, C. (2007). "The changing roles and identities of professional managers in UK higher education." perspectives: policy and practice in higher education 11(2): 53-60.

Whitchurch, C. (2008a). Professional Managers in UK Higher Education: Preparing for Complex Futures. Final Report. London: Leadership Foundation for Higher Education (www.lfhe.ac.uk/publications/research.html).

Whitchurch, C. (2008b). "Beyond Administration and Management: Reconstructing the Identities of Professional Staff in UK Higher Education". Journal of Higher Education Policy and Management 30(4): 387-398.

Whitchurch, C. (2008c). "Shifting Identities and Blurring Boundaries: The Emergence of Third Space Professionals in UK Higher Education". Higher Education Quarterly 62(4): 377-396. 